\title{
Evaluation Index System for Agricultural Water Management in Targeted Poverty Alleviation Based on 3E Model
}

\author{
Yingfeng Chen $\mathbb{D}^{1},{ }^{1}$ Shuyang Zhu $\mathbb{D}{ }^{2}$ and Ming Fan $\mathbb{D}^{1}$ \\ ${ }^{1}$ School of Management, Jiangsu University, Zhenjiang 212013, China \\ ${ }^{2}$ Jiangsu University of Technology, Changzhou 213001, China \\ Correspondence should be addressed to Shuyang Zhu; zhushuyang@jsut.edu.cn \\ Received 26 August 2020; Revised 9 October 2020; Accepted 23 October 2020; Published 1 December 2020 \\ Academic Editor: Rui Wang \\ Copyright $(92020$ Yingfeng Chen et al. This is an open access article distributed under the Creative Commons Attribution License, \\ which permits unrestricted use, distribution, and reproduction in any medium, provided the original work is properly cited. \\ Agricultural water management provides the basic support and guarantee for targeted poverty alleviation. This paper presents a \\ $3 \mathrm{E}+1$ evaluation model for the performance of agricultural water management in targeted poverty alleviation based on $3 \mathrm{E}$ theory, \\ which is more scientific, reasonable, and reliable. On this basis, an evaluation index system including three levels of indicators is \\ designed, and the weight of each evaluation index and performance evaluation model is determined. A case study of a county in \\ the old district of Maoshan in Jiangsu province was conducted using the proposed evaluation theory and methods. The results \\ show that the overall performance of agricultural water management for targeted poverty alleviation in this area was good but \\ needs more improvement in innovation. The evaluation results are roughly consistent with the evaluations of higher authorities, \\ experts, and scholars, which proves that the evaluation system is scientific and reasonable.
}

\section{Introduction}

In the process of targeted poverty alleviation, agricultural water management is essential and indispensable for ensuring rural water safety, improving rural water environment, enhancing agricultural comprehensive productivity, and improving farmers' production and living standards [1]. It is crucial for winning the tough battle against poverty. Since the $18^{\text {th }}$ National Congress of the Communist Party of China, targeted poverty alleviation work has been guided by $\mathrm{Xi}$ Jinping's thought on socialism with Chinese characteristics for a new era. China has been deepening the implementation of the water management policy of "prioritizing water conservation, balanced space, and systemic governance." Adhering to the basic strategy of targeted poverty alleviation and poverty reduction, the Chinese government has put an emphasis on severely impoverished areas and optimized the supply policy by promoting the construction and management of agricultural water conservancy in poor areas. By solidly promoting industry poverty alleviation, designated poverty alleviation, counterpart support, and "five in one" water conservancy poverty alleviation work in the old rural areas, China has been working to win the battle against poverty and build a moderately prosperous society in all respects [2].

Despite the great achievements in agricultural water management for targeted poverty alleviation, the work needs to be scientifically and effectively evaluated. In this way, problems can be identified through evaluation, thus providing a basis for poverty alleviation policy making in the post-poverty alleviation era. For this purpose, it is necessary to design a scientific and reasonable performance evaluation system through quantitative methods. By digging into the problems of agricultural water management for targeted poverty alleviation, the evaluation system can promote the high-quality development of the work and help to establish a long-term agricultural water management mechanism for targeted poverty alleviation in the post-poverty alleviation era. This has become a key scientific frontier issue that needs to be systematically studied and thoroughly discussed.

\section{Method of Constructing Indicator System}

2.1. Construction of a Performance Evaluation Model for Agricultural Water Management in Targeted Poverty 
Alleviation Based on 3E Model. The 3E theory (economy, efficiency, effectiveness) proposed by Professor Checkland (Checkland, PB) based on SSM (soft system methodology) from a system perspective has been regarded as the basic model for public policy evaluation and has become the basis for various late-stage policy evaluations. SSM is a methodology for recognizing and handling complex problems because when soft factors such as politics, society, culture, and human behaviors are mixed into the system, traditional hard system analysis (e.g., modeling profit maximization) often loses its advantages and sometimes fails [3].

The object of performance evaluation is a poverty alleviation method that implements accurate identification, targeted assistance, and management [4], and the evaluation content is the quality and effect of agricultural water management according to targeted poverty alleviation policy [5]. In building a performance evaluation system, it is critically important to decide how to effectively measure whether the allocation and management of resources is reasonable and whether poverty alleviation initiatives are effective as well as the quality of poverty alleviation, outcome satisfaction, and sustainability of targeted poverty alleviation policies [6].

A performance evaluation framework based on $3 \mathrm{E}$ theory can ensure the scientific validity of the performance evaluation of agricultural water targeted poverty alleviation. Therefore, according to the basic paradigm of policy evaluation, this paper details the performance evaluation process into five stages: policy formulation and goal setting, targeted poverty alleviation input, alleviation process, alleviation output, and alleviation outcome, which fully integrates $3 \mathrm{E}$ theory into the whole process to extract the evaluation dimension [7]. Throughout the performance evaluation, targetedness is stressed and is also the essential difference between targeted poverty alleviation and wide-reaching poverty alleviation. Therefore, targetedness needs to be fully reflected in each dimension of the evaluation model [8]. In addition, this paper innovatively incorporates the sustainability of agricultural water management in targeted poverty alleviation into the targeted poverty alleviation evaluation system [9]. This can effectively reflect the sustainability and stability of agricultural water management in targeted poverty alleviation, forming a $3 \mathrm{E}+1$ evaluation model (as shown in Figure 1).

\subsection{Construction of the Index System for Agricultural Water} Management in Targeted Poverty Alleviation. The construction of the performance evaluation index system is a multiobjective and multilevel complex systematic engineering, which should follow the principles of comprehensiveness, scientificity, comparability, operability, and sustainability [10]. The performance evaluation indicators should reflect not only the main contents of the assessment of effectiveness but also the targetedness, stability, and quality of the targeted poverty alleviation work so that the overall evaluation function of the indicator system is greater than the simple accumulation of indicators. It is necessary to build a clear and reasonable hierarchical systematic structure

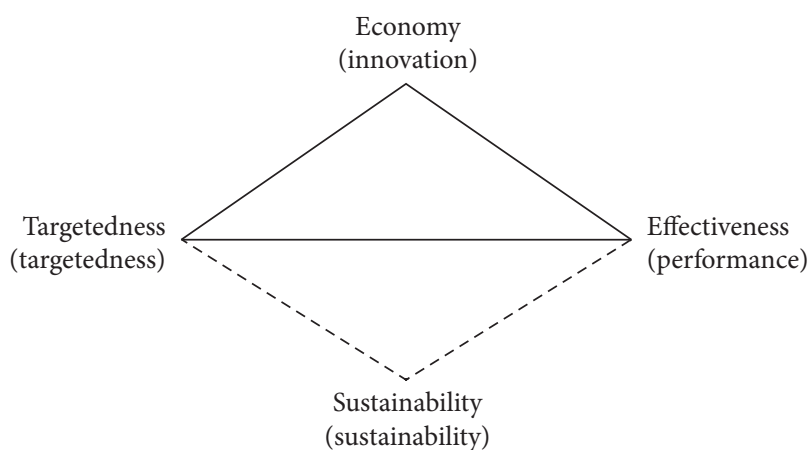

FIgURE 1: The $3 E+1$ evaluation model of the performance of agricultural water management in targeted poverty alleviation.

[11] and avoid overlapping between the indicators while retaining mutual connections [12]. The evaluation indicators established should be universally applicable and feasible [13] and comparable and dynamic for comparisons between different regions, time, and space [14]. Evaluation indicators need to be feasible so the data to be used should be drawn from existing data sources and be verifiable [15]; mutual inclusion and implicit relationship should be avoided; work involved in the evaluation system should also be long-term and continuous [16]. Based on the goals, characteristics, and related literature research of agricultural water management in targeted poverty alleviation [17], the indicator system is designed as Table 1.

2.3. Weight Determination of the Performance Evaluation Index System for Agricultural Water Management in Targeted Poverty Alleviation. This study adopts analytic hierarchy process (AHP) to evaluate and rank the four primary indicators of the performance index system for agricultural water management in targeted poverty alleviation, while the average weighting method is used for the secondary and tertiary indicators. Analytic hierarchy process (AHP), first proposed by Professor Saaty in the 1970s, is a structured decision-making method that combines qualitative and quantitative analyses and is applicable to the analysis of multiple indicator systems [18].

\subsubsection{Construct a Judgment Matrix Based on the Existing} Evaluation System. First, the indicators at the criterion level in the performance evaluation indicators are analyzed, using an AHP analysis model on a scale from 1 to 9. The indicators at the criterion level in the performance evaluation indicators are compared, and a judgment matrix at the four levels of performance, targetedness, innovation, and sustainability is obtained.

From the statistical results, we can conclude that the relative importance values of sustainability to targetedness, performance, and innovation are 3,5, and 7, respectively; the relative importance values of targetedness to performance and innovation are 3 and 6, respectively; the relative importance value of performance to innovation is 4 ; the other two relative importance values can be inferred by analogy from the above results. This leads to the results in Table 2 . 


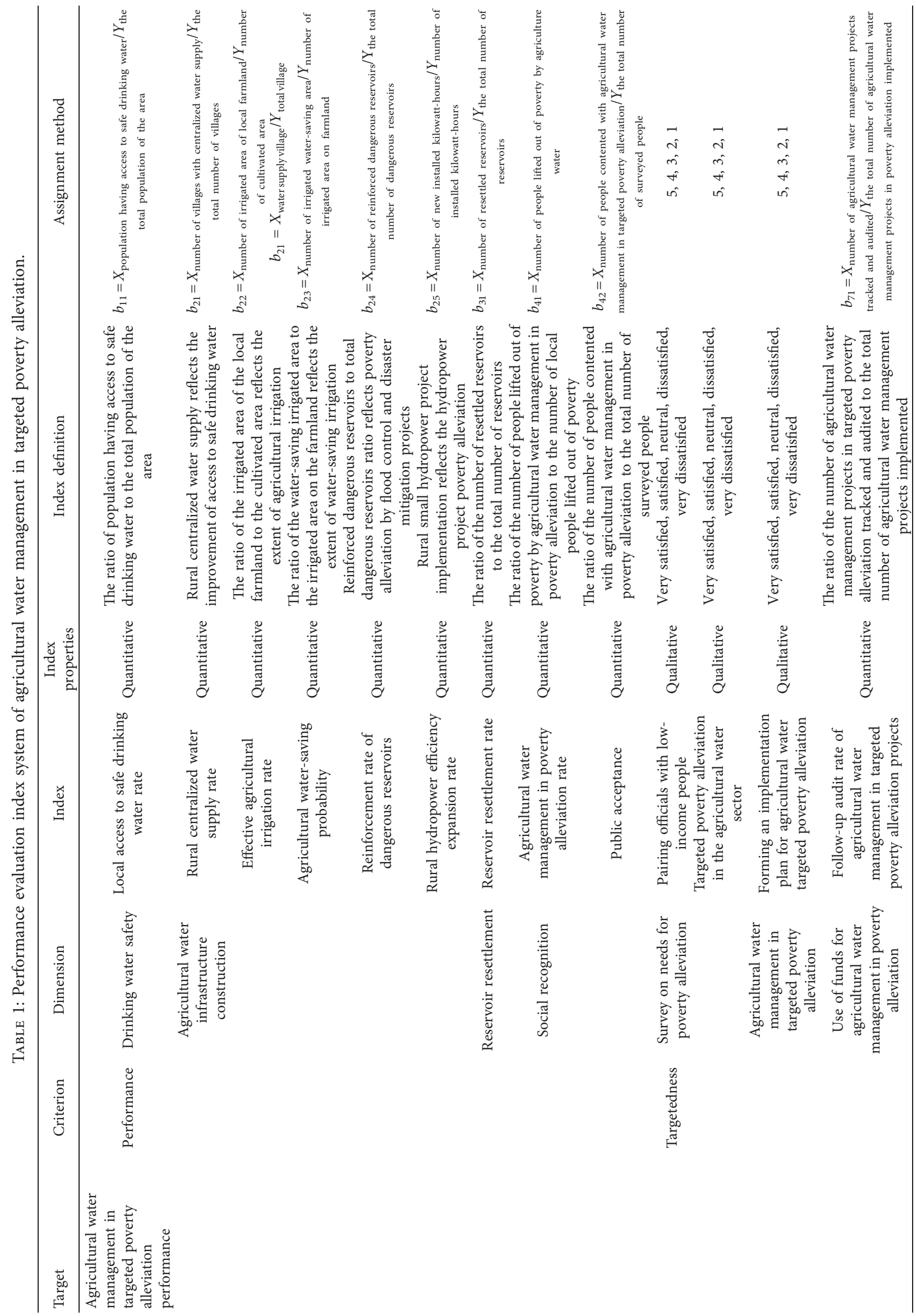




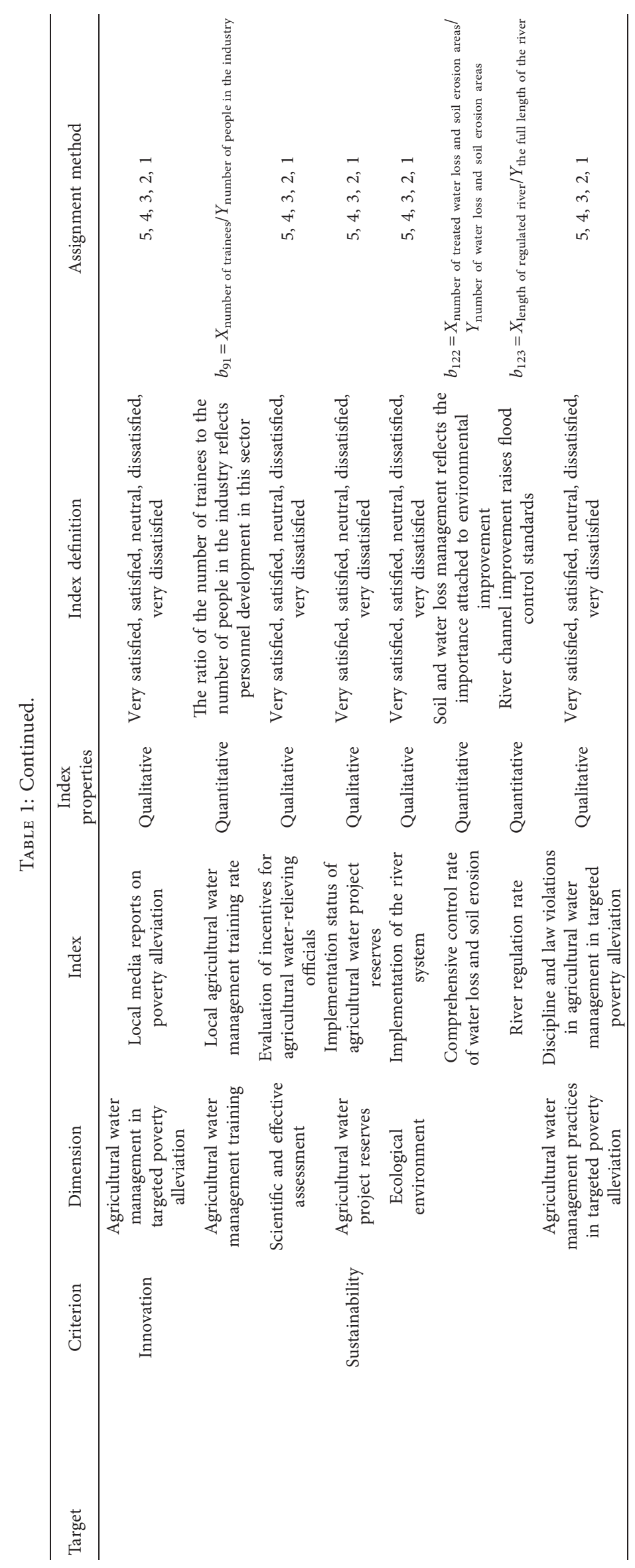


TABLE 2: Weights of the four factors at the criterion level.

\begin{tabular}{lcccc}
\hline Index & Sustainability & Targetedness & Performance & Innovation \\
\hline Sustainability & 1 & 3 & 5 & 7 \\
Targetedness & 0.333333 & 1 & 3 & 6 \\
Performance & 0.200000 & 0.333 & 1 & 4 \\
Innovation & 0.142857 & 0.166667 & 0.250000 & 1 \\
\hline
\end{tabular}

2.3.2. Calculate the Weight Vector. First, calculate each column in the judgment matrix to normalize

$$
W_{j}=\frac{w_{i j}}{\sum_{i=1}^{n} w_{i j}} .
$$

Second, calculate the canonical column average (i.e., the vector of weights sought)

$$
w_{j}^{*}=\frac{\sum_{i=1}^{n} w_{j}}{n} .
$$

Finally, calculate the maximum eigenvalue

$$
\lambda_{\max }=\frac{1}{n} \sum_{1}^{n} \frac{(B W)_{i}}{w_{i}} .
$$

After column normalization, normalizing the average, calculating the maximum eigenvalue, and consistency test, we obtained the weight values between the four factors at the criterion level, and the specific results and calculation process are shown in Table 3.

According to the results of the comparison judgment matrix, after column normalization and normalized averaging using hierarchical analysis (AHP), we obtained the weights of the four indicators of performance, targetedness, innovation, and sustainability. Then, we need to test whether the weight values of the four indicators are acceptable by the consistency test. According to the judgment matrix, the eigenvectors and eigenvalues of the judgment matrix can be obtained: the maximum eigenvalue is 4.182997, and the result of the consistency test $\mathrm{cr}=0.068538<0.1$. At this time, it is considered that the weight given by the criterion level in the performance evaluation index system is acceptable. The results of the weights are 0.548172 for sustainability, 0.269686 for targetedness, 0.130931 for performance, and 0.051212 for innovation [19].

2.4. Construction of Performance Evaluation Model for Agricultural Water Management in Targeted Poverty Alleviation. Considering various characteristic factors in evaluating the performance of agricultural water management in targeted poverty alleviation, this study constructed a model for evaluating the performance, as shown in equation (4).

$$
Z=\sum_{i=1}^{4} Q_{i}\left(\sum_{j=1}^{n} Q_{i j}\left(\sum_{k=1}^{t} Q_{i j k} V_{i j k}\right)\right) .
$$

In this model, $z$ represents the final score of the performance of agricultural water management in targeted poverty alleviation; $Q_{i}$ represents the weight of the first-level indicators, $Q_{i j}$ represents the weight of second-level indicators under each first-level indicator; $n$ represents the number of second-level indicators under each first-level indicator; $Q_{i j k}$ represents the weight of the third-level indicators under the second-level indicators; $t$ represents the number of the thirdlevel indicators under the second-level indicators; and $V_{i j k}$ represents the score value of each third-level indicator.

In order to accurately retain the weight scores of the final indicators of performance evaluation, results of equation (4) are multiplied by 1000 to set the score interval of performance evaluation at $(0-1000)$.

2.5. Performance Evaluation Standards for Agricultural Water Management in Targeted Poverty Alleviation. Since the final performance scores are by multiplied by 1000 in the above evaluation model, the performance evaluation of agricultural water management in targeted poverty alleviation adopts a scoring system ranging from 0 to 1000 , which is set to four levels: excellent (>900), good (800-900, including 800), moderate $(600-800$, including 600$)$, and poor $(<600)$.

\section{Application of Performance Evaluation for Agricultural Water Management in Targeted Poverty Alleviation in a County in the Old District of Maoshan in Jiangsu}

Theoretical basis and performance evaluation system only address the concept and operational methods of performance evaluation of agricultural water management in targeted poverty alleviation from a theoretical point of view. To test whether the method is practical and operable, it should also be applied to the case study. Therefore, a county in the old district of Maoshan in Jiangsu province is chosen as an example to comprehensively evaluate the performance of agricultural water management in targeted poverty alleviation by applying the performance evaluation theory and index system proposed in this paper.

3.1. Overview of the County in Case Study. Located in the old district of Maoshan in the southwest of Jiangsu province, the county covers an area of 1,535 square kilometers, including 1.12 million $\mathrm{mu}$ of the cultivated land, $328,000 \mathrm{mu}$ of the forest land, and 426,000 mu of rivers and lakes. There are many types of landforms such as low mountains, hills, and plains in the area. The southern, western, and northern sections are higher, and the intermediate, central, and eastern sections are flatter. The south is a low area with steeper mountains; the northwest is a hilly area with rolling hills; the intermediate and central areas are flat from west to east and 
TABLE 4: Performance scores of agricultural water management in targeted poverty alleviation in a county in the old district of Maoshan in Jiangsu.

\begin{tabular}{|c|c|c|c|c|}
\hline Criterion & Dimension & Index & $\begin{array}{l}\text { Standard } \\
\text { score }\end{array}$ & $\begin{array}{c}\text { Score } \\
\text { (points) }\end{array}$ \\
\hline \multirow{9}{*}{$\begin{array}{l}\text { Performance } \\
(A)\end{array}$} & Drinking water safety $\left(A_{1}\right)$ & Local access to safe drinking water rate $\left(A_{11}\right)$ & 33 & 33 \\
\hline & \multirow{5}{*}{$\begin{array}{l}\text { Agricultural water infrastructure } \\
\text { construction }\left(A_{2}\right)\end{array}$} & Rural centralized water supply rate $\left(A_{21}\right)$ & 7 & 7 \\
\hline & & Effective agricultural irrigation rate $\left(A_{22}\right)$ & 7 & 7 \\
\hline & & Agricultural water-saving pipes probability $\left(A_{23}\right)$ & 7 & 3 \\
\hline & & Reinforcement rate of dangerous reservoirs $\left(A_{24}\right)$ & 7 & 5 \\
\hline & & Rural hydropower efficiency expansion rate $\left(A_{25}\right)$ & 7 & 5 \\
\hline & Reservoir resettlement $\left(A_{3}\right)$ & Reservoir resettlement rate $\left(A_{31}\right)$ & 33 & 30 \\
\hline & \multirow{2}{*}{ Social recognition $\left(A_{4}\right)$} & Poverty alleviation rate $\left(A_{41}\right)$ & 16 & 16 \\
\hline & & Mass recognition $\left(A_{42}\right)$ & 16 & 12 \\
\hline \multirow{4}{*}{$\begin{array}{l}\text { Targetedness } \\
(B)\end{array}$} & $\begin{array}{l}\text { Surveys on the need for agricultural water } \\
\text { management in targeted poverty alleviation }\end{array}$ & $\begin{array}{l}\text { Pairing situation between agricultural water } \\
\text { management officials and low-income people } \\
\qquad\left(B_{11}\right)\end{array}$ & 45 & 45 \\
\hline & $\left(B_{1}\right)$ & $\begin{array}{l}\text { Targeted poverty alleviation by agricultural water } \\
\text { management department }\left(B_{12}\right)\end{array}$ & 45 & 45 \\
\hline & $\begin{array}{l}\text { Agricultural water management in targeted } \\
\text { poverty alleviation }\left(B_{2}\right)\end{array}$ & $\begin{array}{l}\text { Forming an implementation plan for agricultural } \\
\text { water targeted poverty alleviation }\left(B_{21}\right)\end{array}$ & 90 & 90 \\
\hline & $\begin{array}{l}\text { Use of the funds for agricultural water } \\
\text { management in targeted poverty alleviation } \\
\qquad\left(B_{3}\right)\end{array}$ & $\begin{array}{c}\text { Follow-up audit rate of agricultural water } \\
\text { management projects in targeted poverty } \\
\text { alleviation }\left(B_{31}\right)\end{array}$ & 90 & 90 \\
\hline \multirow{3}{*}{ Innovation $(C)$} & $\begin{array}{l}\text { Agricultural water management in targeted } \\
\text { poverty alleviation }\left(C_{1}\right)\end{array}$ & $\begin{array}{l}\text { Local media reports on agricultural water } \\
\text { management in poverty alleviation }\left(C_{11}\right)\end{array}$ & 17 & 9 \\
\hline & $\begin{array}{c}\text { Agricultural water management personnel } \\
\text { training }\left(C_{2}\right)\end{array}$ & $\begin{array}{l}\text { Local agricultural water management personnel } \\
\text { training rate }\left(C_{21}\right)\end{array}$ & 17 & 8 \\
\hline & Scientific and effective assessment $\left(C_{3}\right)$ & $\begin{array}{c}\text { Evaluation of incentives among officials of } \\
\text { agricultural water management in poverty } \\
\text { alleviation }\left(C_{31}\right)\end{array}$ & 17 & 10 \\
\hline \multirow{5}{*}{$\begin{array}{l}\text { Sustainability } \\
(D)\end{array}$} & $\begin{array}{c}\text { Agricultural water management project } \\
\text { reserves }\left(D_{1}\right)\end{array}$ & $\begin{array}{l}\text { Implementation status of agricultural water } \\
\text { management project reserves }\left(D_{11}\right)\end{array}$ & 183 & 164 \\
\hline & & Implementation of the river system $\left(D_{21}\right)$ & 61 & 61 \\
\hline & Ecological environment $\left(D_{2}\right)$ & $\begin{array}{l}\text { Comprehensive treatment rate of soil erosion } \\
\qquad\left(D_{22}\right)\end{array}$ & 61 & 61 \\
\hline & & River regulation rate $\left(D_{23}\right)$ & 61 & 55 \\
\hline & $\begin{array}{l}\text { Practices in agricultural water management } \\
\text { in targeted poverty alleviation }\left(D_{3}\right)\end{array}$ & $\begin{array}{l}\text { Discipline and law violations in agricultural water } \\
\text { management in targeted poverty alleviation }\left(D_{31}\right)\end{array}$ & 183 & 183 \\
\hline \multicolumn{3}{|c|}{ Performance evaluation score of agricultural water management in targeted poverty alleviation } & 1000 & 939 \\
\hline
\end{tabular}

the standardization of agricultural water management in targeted poverty alleviation work and strengthen the innovation of targeted poverty alleviation work in the field of agricultural water conservancy so as to improve the quality and efficiency of targeted poverty alleviation work.

\section{Conclusion}

Based on $3 \mathrm{E}$ theory, this paper builds a $3 \mathrm{E}+1$ performance evaluation model of agricultural water management in targeted poverty alleviation, which improves the scientificity, rationality, and reliability of the performance evaluation. On this basis, a performance evaluation index system was designed, the corresponding index weights were determined, and the evaluation model was constructed. Based on this, a case study was applied to a county in the old district of Maoshan, Jiangsu. By analyzing the development of agricultural water management in targeted poverty alleviation work in the county in 2019 , it is concluded that the performance evaluation results of agricultural water management in targeted poverty alleviation are basically consistent with the performance analyses of higher-level departments, relevant experts, and scholars, which proves that the theory and method proposed in this paper are scientific and applicable. However, in the practice of performance evaluation, it is still necessary to appropriately revise the evaluation method according to the characteristics and development changes of the evaluation object in order to obtain more reasonable and reliable evaluation results.

\section{Data Availability}

The data used to support the findings of this study are available from the corresponding author upon request.

\section{Conflicts of Interest}

All authors declare that they have no conflicts of interest.

\section{Acknowledgments}

This work was supported by the Major Project of Philosophy and Social Science Research in Universities of Jiangsu Provincial Department of Education in 2020. 


\section{References}

[1] Z. C. Hui, "Give full play to the supporting role of the water conservancy industry and help to take the lead in winning the tough battle against poverty," in Procedings of the Annual Conference of the Chinese Water Conservancy Society, pp. 2205, Sichuan, China, October 2016.

[2] P. B. Checkland, "Towards a system-based methodology for real-word problem solving," Journal of system Engineering, vol. 3, pp. 87-116, 1972.

[3] P. B. Checkland, "Towards a system-based methodology for real-word problem solving," Journal of Applied System Engineering, vol. 3, pp. 87-116, 1972.

[4] S. G. Wang and Z. H. Guo, "On China's targeted poverty alleviation," Guizhou Social Sciences, vol. 5, pp. 147-150, 2015.

[5] W. L. Jiang, "Research on the characteristics of precise poverty alleviation in water conservancy and its performance evaluation system," in Proceedings of Annual Conference of the Chinese Water Conservancy Society, pp. 244-247, Sichuan, China, October 2016.

[6] R. Wang, R. C. Purshouse, and P. J. Fleming, "Preferenceinspired coevolutionary algorithms for many-objective optimization," IEEE Transactions on Evolutionary Computation, vol. 17, no. 4, pp. 474-494, 2013.

[7] L. Sun, Research on Performance Evaluation of Poverty Alleviation Project, China Agricultural University, Beijing, China, 2015.

[8] Y. Fu and Y. R. Zhang, "Performance evaluation of poverty alleviation and development in Lanzhou city and its enlightenment," Journal of Hunan Agricultural University (Social Science Edition), vol. 12, no. 5, pp. 25-30, 2011.

[9] R. Wang, Z. Zhou, H. Ishibuchi, T. Liao, and T. Zhang, "Localized weighted sum method for many-objective optimization," IEEE Transactions on Evolutionary Computation, vol. 22, no. 1, pp. 3-18, 2018.

[10] K. Li, R. Wang, T. Zhang, and H. Ishibuchi, "Evolutionary many-objective optimization: a comparative study of the state-of-the-art," IEEE Access, vol. 6, pp. 26194-26214, 2018.

[11] C. X. Liu, H. F. Zhao, and L. X. Wei, "An empirical study on the performance evaluation index system of Guangxi villagelevel targeted poverty alleviation," Forestry Economics, vol. 10, p. 31, 2018.

[12] Y. Dai, "Construction and application of the index system for the performance evaluation of targeted poverty alleviation work," World of Labor Security, vol. 5, p. 23, 2017.

[13] S. P. Hu, "Research on the construction of the index system for performance evaluation of precise poverty alleviation," Journal of Shenyang Agricultural University (Social Science Edition), vol. 18, no. 5, pp. 513-520, 2016.

[14] C. G. Zhang, "On the construction of an indicator system for the comprehensive construction of a well-off society in rural areas," Journal of Theoretical Sciences, vol. 1, pp. 32-33, 2006.

[15] Q. Zhang and Z. L. Shi, "Construction of performance evaluation index system for poverty alleviation in my country," Education and Economics, vol. 4, p. 38, 2018.

[16] A. X. Chen and Y. Liu, "Research on the performance evaluation of the implementation of targeted poverty alleviation in my country by AHP," Journal of Huaqiao University (Philosophy and Social Sciences Edition), vol. 1, pp. 116-129, 2017.

[17] W. Lei, C. Zhang, and L. Liu, "Research on Guizhou province water conservancy targeted poverty alleviation implementation evaluation index system," Journal of Irrigation and Drainage, vol. 12, pp. 127-130, 2018.
[18] X. Yang, "Research on performance evaluation of poverty alleviation projects from a precise perspective," Financial Economy, vol. 2, pp. 23-25, 2017.

[19] R. Wang, Q. Zhang, and T. Zhang, "Decomposition-based algorithms using pareto adaptive scalarizing methods," IEEE Transactions on Evolutionary Computation, vol. 20, no. 6, pp. 821-837, 2016. 